\title{
Real-world data in the United Kingdom: opportunities and challenges
}

\author{
Laura McDonald, Dimitra Lambrelli, Radek Wasiak and Sreeram V. Ramagopalan*
}

\begin{abstract}
Real-world data is that collected outside the constraints of controlled clinical trials and is increasingly informing decision-making in healthcare. The landscape of real-world data in the United Kingdom is set to evolve over the coming months as the government plans to build on databases currently in place by collecting patient data from all family practices and linking this information with hospital records. This initiative, called care.data, has the potential to be an invaluable resource. However, the programme has been criticized on grounds of data privacy, which has led to an extended delay in its implementation and the expectation that a large number of people will opt out. Opt-outs may introduce substantial biases to the dataset, and understanding how to account for these presents a significant challenge for researchers. For the scope and quality of real-world evidence in the United Kingdom to be realised, and for this information to be used effectively, it is essential to address this challenge.
\end{abstract}

Keywords: Real-world evidence, Care.data, United Kingdom

\section{Background}

Real-world data has been defined by the Association of the British Pharmaceutical Industry as data collected outside the controlled constraints of conventional randomised clinical trials to evaluate what is happening in routine clinical practice [1]. While clinical trials provide the 'gold standard' for establishing treatment efficacy, they are conducted in small populations under tightly controlled conditions and thus alone are insufficient to guide clinical practice [2]. As a result, real-world data have become important components for healthcare decision-making [3]. By operating outside the confines of clinical trials, real-world data can be used to understand treatment effectiveness as well as to provide insight into patterns of care, long-term drug safety, healthcare resource utilisation and disease epidemiology.

The routine implementation of electronic medical records, as well as technological advances that have allowed for the safe storage and sharing of data, have provided an unparalleled opportunity to gather and use real-world data to inform decision-making in healthcare. With a national health service (NHS) and general practitioners (GP) acting as gatekeepers to secondary care, the

\footnotetext{
* Correspondence: sreeram.ramagopalan@evidera.com

Evidera, Metro Building, 6th Floor, 1 Butterwick, W6 8DL, London, UK
}

United Kingdom (UK) is uniquely positioned to collate rich data across its network of healthcare providers.

The Clinical Practice Research Datalink (CPRD) is one of the UK's existing primary care databases, which for over two decades has extracted anonymised medical records from hundreds of GP practices and has helped to inform broad issues in patient care. The database currently has 4.4 million active patients, reflecting $6.9 \%$ of the UK population [4]. Although working with 'big data' requires an understanding of how information is collected and coded, effective strategies can be developed to recode what are complex raw data for actionable scientific analysis and insight generation. Variation in disease coding (or failure to code) and differences in missing data across patients and time, as well as data not being captured at all, require effortful consideration on the part of researchers. Nevertheless, the sharing of CPRD data for research purposes has generated over 1000 peer-reviewed publications, with notable contributions including work confirming the safety of the measles, mumps and rubella vaccine [5], fracture risk associated with thiazolidinediones [6] and work demonstrating the association between body mass index and cancer risk [7]. 


\section{Care.data - opportunities and challenges}

In light of the CPRD's success and with a view to improving service commissioning across the breadth of the NHS, the government has planned to extend the reach of healthcare data collection to all GP practices in the UK, and to link this information with hospital records overseen by the Health and Social Care Information Centre (HSCIC). The initiative, called care.data, was introduced in 2013 under the tagline 'Better Information Means Better Care'. The programme will require all GP practices in the UK to submit data, although each patient maintains the authority to opt-out and sensitive data, such as information related to sexual health, assisted conception, imprisonment or abuse, will not be extracted. As has been the case with the CPRD, patient records will be anonymised and shared with approved third parties after scientific committee approval for observational research purposes.

Care.data has the potential to be an invaluable source of real-world data in the UK. The main advantage of the larger sample size is greater statistical power and the ability to look at more determinants. This is especially important for investigating rare diseases or rarer adverse events from treatments. The database will also overcome some of the limitations of CPRD by having primary and secondary care information already linked (although some information, such as treatments given in hospital, may remain uncaptured).

Despite the potential value of the database, balancing the need for well-conducted observational research with the patient's right to confidentially has thus far proved challenging. This was illustrated when the introduction of the care.data programme in 2013 was met by widespread criticism with concerns raised regarding the sharing of personal data without explicit consent, the distribution of sensitive data to third parties and data safeguarding. Mismanagement and poor communication from the government regarding these issues resulted in an extended delay in implementation. In September 2015, the government commissioned a review into data-sharing practices in the UK, which will go to public consultation after the EU 'Brexit' referendum in June 2016. When the care.data programme is eventually resurrected, a large number of opt-outs should be expected, with initial suggestions showing more than 1 million patients, or $2.2 \%$ of the NHS's 56 million patients already choosing to have their data removed [8]. This number of opt-outs, if occurring non-randomly, has the potential to introduce substantial biases into the extracted dataset. Understanding how to identify and account for any biases, as well as the incomplete variable coverage, presents a significant challenge for researchers using care.data [9].

Importantly, auto-enrolment with the option to opt-out offers a substantially more effective and representative method for participant recruitment than an opt-in approach. Previous work has shown that recruiting participants to an observational medical database via an opt-in strategy compared to an opt-out approach resulted in significantly lower recruitment rates and a biased sample, such that those patients included tended to be healthier on multiple indicators [10]. Equally, a Canadian stroke registry requiring explicit consent led to selection biases in key demographic and clinical characteristics known to be associated with long-term patient outcomes [11]. When creating a national resource for healthcare data, an opt-in approach to participant recruitment has the potential to leave those patients most requiring care unaccounted for.

The impact of opt-outs on medical records data, however, has not yet been well-defined. For example, in a United States birth cohort, the introduction of optout legislation led to significant differences in ethnicity and maternal age between families who were included and those who opted-out [12]. This suggests sociodemographic factors influence decisions to opt out, which could bias the sample. However, other work in a cohort being treated for a urinary tract infection found no differences in age, gender and one clinical characteristic (urine test) between patients choosing to opt-out and those included in the final sample [13]. These are, however, small studies $(n<2000)$ including only limited clinical indicators. Clearly, more work is needed to identify the socio-demographic and clinical characteristics of patients choosing to opt-out in order to understand how this may reduce the value of the data.

\section{Conclusions}

Even in view of the large number of expected optouts, it is important to consider that surveys show most patients are supportive of medical records research [14, 15]. Indeed, Nordic countries have established national mandatory health registries with great success $[16,17]$. In these regions, provision of data is seen as part of the contract for receiving free healthcare, and ethical review committees help ensure data are handled in a way that maintains patient privacy [18]. In the UK, any decision to opt-out is likely to be driven by the patient's perception of the risks and benefits involved in sharing their data [15]. Importantly, adequately framing arguments around privacy concerns has been shown to generate more positive attitudes [19]. Therefore, appropriate information needs to be channelled to groups that may be misinformed or to those patients who may desire more information. Patients also need to be engaged, for example, by receiving information on how their data are being used [20]. However the challenge of opt-outs are met, adequately addressing the issue will be essential to ensure the scope and quality of 
observational research generated using care.data are not compromised, and to continue building on the successes of existing databases such as the CPRD.

\section{Acknowledgements}

The authors would like to gratefully acknowledge Victoria Clift-Matthews for copy-editing the manuscript.

\section{Funding}

No external funding was provided.

\section{Authors' contributions}

SR and LM drafted the initial manuscript. All authors critically reviewed the manuscript and approved the final manuscript as submitted.

\section{Competing interests}

All authors are employees of Evidera Inc., a contract research organisation providing research and consultancy support for pharmaceutical companies in using real-world data.

\section{Published online: 24 June 2016}

\section{References}

1. The Association of the British Pharmaceutical Industry. The vision for real world data - harnessing the opportunities in the uk demonstrating value with real world data acknowledgements. 2011. http://www.abpi.org.uk/ourwork/library/industry/Documents/Vision-for-Real-World-Data.pdf. Accessed 22 June 2016.

2. Nallamothu BK, Hayward RA, Bates ER. Key issues in outcomes research beyond the randomized clinical trial the role of effectiveness studies in evaluating cardiovascular therapies. Circulation. 2008;1 18:1294-303. doi:10.1161/CIRCULATIONAHA.107.703579.

3. Garrison L, Neumann PJ, Erickson P, Marshall D, Mullins CD. Using real-world data for coverage and payment decisions: The ISPOR Real-World Data Task Force Report. Value Heal. 2007;10(5):326-35.

4. Herrett E, Gallagher AM, Bhaskaran K, et al. Data resource profile: Clinical Practice Research Datalink (CPRD). Int J Epidemiol. 2015:44(3):827-36. doi:10.1093/ije/dyv098.

5. Smeeth L, Cook C, Fombonne E, et al. MMR vaccination and pervasive developmental disorders: a case-control study. Lancet. 2004;364(9438):963-9. doi:10.1016/S0140-6736(04)17020-7.

6. Douglas IJ, Evans SJ, Pocock S, Smeeth L. The risk of fractures associated with thiazolidinediones: a self-controlled case-series study. PLoS Med. 2009; 6(9):e1000154. doi:10.1371/journal.pmed.1000154

7. Bhaskaran K, Douglas I, Forbes H, dos-Santos-Silva I, Leon DA, Smeeth L. Body-mass index and risk of 22 specific cancers: a population-based cohort study of 5.24 million UK adults. Lancet. 2014;384(9945):755-65. doi:10.1016/S0140-6736(14)60892-8.

8. Shah S. HSCIC finally agrees to implement opt-outs for care.data. 2016. http://www.computing.co.uk/ctg/news/2456370/hscic-finally-agrees-toimplement-opt-outs-for-caredata. Accessed 31st May 2016

9. Hernán MA, Hernández-Díaz S, Robins JM. A structural approach to selection bias. Epidemiology. 2004;15(5):615-25. doi:10.1097/01.ede.0000135174.63482.43.

10. Junghans $C$, Feder $G$, Hemingway $H$, Timmis A, Jones M. Recruiting patients to medical research: double blind randomised trial of "opt-in" versus "optout" strategies. BMJ. 2005;331(7522):940. doi:10.1136/bmj.38583.625613.AE.

11. Tu JV, Willison DJ, Silver FL, et al. Impracticability of informed consent in the Registry of the Canadian Stroke Network. N Engl J Med. 2004;350:1414-21. doi:10.1056/NEJMsa031697.

12. Gill S, Miller S, Broussard C, Reefhuis J. The effects of opt-out legislation on data collection and surveillance of birth defects by the New Hampshire Birth Conditions Program, New Hampshire, United States, 2007-2009. J Registry Manag. 2012;39(1):19-23.

13. Vellinga A, Cormican M, Hanahoe B, Bennett K, Murphy AW. Opt-out as an acceptable method of obtaining consent in medical research: a short report. BMC Med Res Methodol. 2011:11:40. doi:10.1186/1471-2288-11-40.

14. Cousins G, McGee H, Ring L, et al. Public perceptions of biomedical research: a survey of the general population in Ireland. Dublin: Health Research Board; 2005.

15. Barrett G, Cassell JA, Peacock JL, Coleman MP, National Cancer Registry. National survey of British public's views on use of identifiable medical data by the National Cancer Registry. BMJ. 2006;332(7549):1068-72. doi:10.1136/bmj.38805.473738.7C.

16. Emilsson L, Lindahl B, Koster M, Lambe M, Ludvigsson JF. Review of 103 Swedish healthcare quality registries. J Intern Med. 2015;277(1):94-136. doi:10.1111/joim.12303.

17. Wettermark B, Hammar N, MichaelFored C, et al. The new Swedish Prescribed Drug Register-Opportunities for pharmacoepidemiological research and experience from the first six months. Pharmacoepidemiol Drug Saf. 2007;16(7):726-35. doi:10.1002/pds.1294.

18. Ludvigsson JF, Haberg SE, Knudsen GP, et al. Ethical aspects of registrybased research in the Nordic countries. Clin Epidemiol. 2015;7:491-508. doi:10.2147/CLEP.S90589.

19. Caligtan CA, Dykes PC. Adoption of electronic health records in the presence of privacy concerns: The elaboration likelihood model and individual persuasion. MIS Q. 2009:33(2):339-70. doi:10.1016/.j.soncn.2011.04.007.

20. Kaye J, Whitley EA, Lund D, Morrison M, Teare H, Melham K. Dynamic consent: a patient interface for twenty-first century research networks. Eur J Hum Genet. 2014;23(10):141-6. doi:10.1038/ejhg.2014.71.

\section{Submit your next manuscript to BioMed Central and we will help you at every step:}

- We accept pre-submission inquiries

- Our selector tool helps you to find the most relevant journal

- We provide round the clock customer support

- Convenient online submission

- Thorough peer review

- Inclusion in PubMed and all major indexing services

- Maximum visibility for your research

Submit your manuscript at www.biomedcentral.com/submit
Biomed Central 